\title{
A propósito de la telefonía móvil Una reflexión desde la perspectiva de la psicología individual y social
}

\author{
Dra. $\mathrm{M}^{\mathrm{a}}$. Dolores Otero Castelló \\ Profesora Titular de Ciencias Psicosociales Aplicadas. Universidad de Sevilla. \\ Médico. Especialista en Psiquiatría. Psicoterapeuta.
}

"La vida examinada es la única que merece la pena ser vivida".

Sócrates

\section{RESUMEN}

Hace poco la revista ne.com, titulaba un editorial: "Telefonía móvil. Una nueva era". ¿En lo tecnológico, lo económico, lo social...? El texto aclara "La madurez de la telefonía móvil, que ha tenido una niñez muy rápida, está suponiendo y va a suponer aún más en un futuro ya casi inmediato, todo un cambio fundamental, tanto en las RELACIONES SOCIALES como en el mundillo de los negocios...”(2001:1; las letras en caja alta son mías) ¿De qué forma? ¿Hasta qué punto? ???? Surgen múltiples interrogantes.

Al abordar este trabajo teórico y reflexivo, asumo dos premisas, fácilmente deducibles del epígrafe elegido, que constituyen las coordenadas que lo delimitan y concretan.

En primer lugar, no me propongo responder, categórica e inequívocamente, a las cuestiones que, la Telefonía Móvil, en su relación con las vertientes psíquicas y psicosociales del ser humano, puede plantear. Una somera reflexión nos evidencia la multiplicidad de modelos, teorías, abordajes metodológicos, variables, contextos, etc., que habría que definir y contemplar, así como las posibles cuestiones a responder: ¿A quién? ¿Cómo? ¿En qué forma?....

En segundo lugar, aunque la Telefonía Móvil, como tecnología que permite la comunicación con cada vez más insignificantes limitaciones, es el foco de interés prioritario y básico de determinados campos científicos, a mí me interesa enfocar este estudio en el instrumento que la operativiza, que la pone, nunca mejor dicho, en la "mano" y en la intimidad del "hombre", la “mujer”, el "joven”, el “¿niño?”, el “¿anciano?”, (No siendo este orden ni los signos ortográficos en absoluto arbitrarios): EL MÓVIL.

Por ello me decanto por un tratamiento analítico, más vigoroso que riguroso, de aquellos aspectos que he considerado significativos, para poder concluir, si, más que la Telefonía Móvil en general, en concreto el Móvil, por sí mismo, y no sólo como un instrumento más de la Edad de la Comunicación, constituye o no un factor determinante del devenir personal; no me ocuparé en este trabajo del colectivo, como parece desprenderse de la titulación reseñada.

En resumen, el análisis se referirá al binomio relacional MÓVIL-PERSONA

\section{ABSTRACT}

A short time ago the magazine ne. com. Gave tittle to an article in these terms: "Mobile Telephony. A new era". Technologicaly, economically, or socially...?. The text explains "The maturity of mobile telephony, wich has had a fast childhood, is causing and it will cause in a near future, a deep change, in SOCIAL RELATIONS as well as in the business world..." (2001:1). In which way? To what extent??? Many questions appear. 
Dealing with this theoretical and reflected piece of work, I assume two premises, which may define the selected topic.

Firstly it is not my intention to give an answer to the questions that the Mobile Telephony could raise in relation to the psychic and psychosocial aspects of the human being. A simple reflexion shows the multiplicity of models, theories, methodological approaches, variables, contexts, etc... That should be defined and taken into account and questions like: To whon?, How?, In which way?... sould be answered.

Secondly, even if thew Mobile Telephony, allows comunications with a very few limitations and it is the main interest of particular scientific fields, I am interested in focussing this report on the tool that makes that comunication effective, that gives it to the "hand" and to the privacy of "men”, "women”, “young people”, “children?”, "elderly people?”, (Order and spelling-marks are not arbitrary): This tool is THE MOBILE.

For all these reasons, I choose an analytical aproach, more vigorous than rigorous, to those significant aspects, to be able to conclude, if specifically, the Mobile,

by itself, and not as an instrument more of the Comunication Era, is or it is not a determining factor of personal evolution. So, I will not deal with the group, but the relational binomial MOBILE-PERSON.

Palabras claves: Telefonía móvil/Relaciones sociales/Vertientes psíquicas y psicsociales/Binomio relacional Móvil-Persona.

Key Words: Mobile telephony/Social relations/Psychic and psychosocial aspects/Relational binomial Mobile-Person.

\section{La telefonía movil: la historia y los datos.}

n Europa la telefonía móvil va a cumplir 19 años. En junio de 1982 ,
Telefónica, tras tres años de experimentación, inaugura su red de telefo-
nía celular NMT-450. Esta compañía fue pionera en nuestro continente
junto a la de los países escandinavos. La Conferencia Europea de Correos y Telecomunicaciones (CEPT) crea un grupo de trabajo encargado de especificaciones y estándares del nuevo sistema de telecomunicaciones móviles para el ámbito europeo. Telefónica, la primera operadora española, firma los acuerdos en 1987 y preside la comisión en 1991.

Es, precisamente, al principio de los noventa cuando se presenta comercialmente la telefonía móvil en España. "Desde hace apenas un quinquenio, los primitivos equipos analógicos han quedado reducidos a una presencia testimonial, siendo sustituidos por los terminales digitales que, según se prevé, con la llegada de la nueva tecnología UMTS (universal mobile telecomunications system) sufrirá la misma suerte.".(ed.cit)

La evolución del número de terminales en España desde 1994 hasta el 2000 se refleja en los siguientes diagramas. Aunque Javier Conty (Director comercial de Sigma Solutions, consultora de tecnología de la información), en un artículo publicado en la ya citada revista ne.com, cifra la cuantía de terminales en España en 24.000.000. (2001:4). 


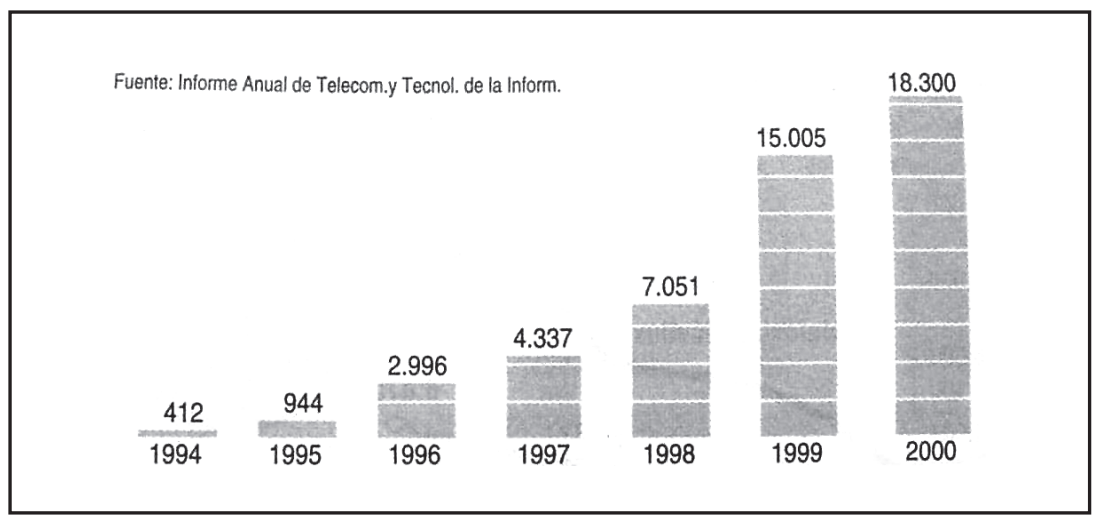

Evolución del número de terminales en España (1994-2000)

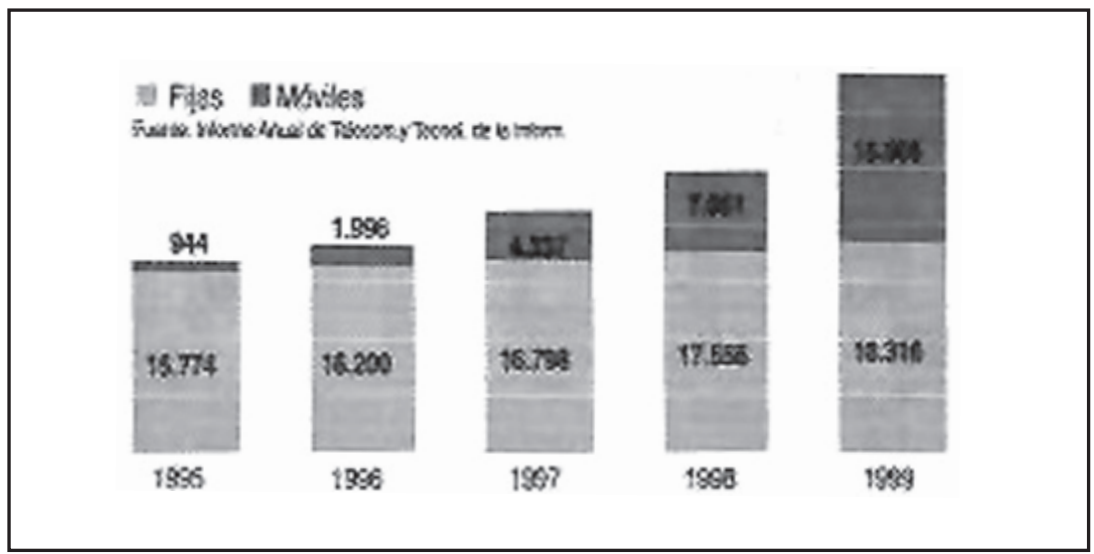

Evolución de la relación fijos-móviles en España (1995-1999)

Con respecto a las previsiones de futuro, nos parece ilustrativo lo que aporta el autor citado anteriormente en el mismo artículo: "los usuarios demandan nuevas prestaciones, tales como acceso a bases de datos y múltiples servicios.... Esto es lo que proporciona la nueva generación de teléfonos móviles, veremos a las personas no solo hablando mientras se mueven, sino también intercambiando textos, datos, música, fotos, incluso imágenes en vivo....Las nuevas generaciones de móviles redefinirán nuestros modos de trabajo y comunicación en los próximos años"(art.cit).

Por último, me parece interesarte incluir una tabla de ordenación de países realizada en función de un índice elaborado por la consultora Research Associates, valorando su capacidad para acceder a las redes de telecomunicaciones informatizadas y generar contenidos, incluyendo 23 categorías. 
1. SUECIA

2. U.S.A

3. FINLANDIA

4. NORUEGA

5. DINAMARCA

6. CANADÁ

7. HOLANDA

8. SUIZA

9. AUSTRALIA

10. JAPÓN

11. SINGAPUR

12. GRAN BRETAÑA

13. ALEMANIA

14. HONG KONG

15. BÉLGICA

16. AUSTRIA

17. NUEVA ZELANDA
18. TAIWAN

19. IRLANDA

20. ISRAEL

21. FRANCIA

22. COREA

23. ITALIA

24. ESPAÑA

25. EMIRATOS ÁRABES

26. PORTUGAL

27. CHEQUIA

28. HUNGRÍA

29. GRECIA

30. POLONIA

31. RUMANIA

32. CHILE

33. ARGENTINA

34. COSTA RICA
35. MALASIA

36. BULGARIA

37. PANAMÁ

38. SUDAFRICA

39. VENEZUELA

40. RUSIA

41. A. SAUDÍ

42. BRASIL

43. ECUADOR

44. MÉXICO

45. TURQUIA

46. COLOMBIA

47. FILIPINAS

48. TAILANDIA

49. JORDANIA

50. EGIPTO

\section{El objeto: el movil/los móviles.}

Hace unos 8 años vi por primera vez el pequeño teléfono. Lo tenía un querido amigo, director en mi ciudad, capital provincial y autonómica, de una importante empresa de ámbito nacional. Despertó mi curiosidad, más que por sus cualidades intrínsecas, su aspecto, color o sonido, porque intuí que estaba accediendo a un nuevo objeto, en aquel momento asociado a un status de poder.

Cuando sonó, lo sacó del bolsillo exterior de su chaqueta con cierta dificultad, y casi podría decir que se justificó por tenerlo: "Lo requiero para mi trabajo", y no sé si como respuesta a una pregunta mía, me hizo saber el elevado coste del artilugio. Los aspectos técnicos y científicos no fascinaron a una humanista como yo, y para mi propia vida y actividad no lo consideré necesario ni interesante, y mucho menos a ese coste, así que durante un tiempo no volví a pensar en ello.

Ese primer móvil, ese otro tentáculo de la globalización, se ha reproducido exponencialmente, regado, como si de un "gremlin" se tratara, por la publicidad al servicio de la sociedad de consumo y sus estructuras económicas. De ese primigenio MÓVIL hemos pasado a LOS MÓVILES, o mejor a MÍ, TU, SU MÓVIL, de diferentes marcas, operadoras, coberturas, tamaños, prestaciones, colores y precios.

El análisis de los factores de orden económico, técnico o empresarial que puedan estar en la base de este fenómeno escapa a los objetivos de este trabajo, y la profundización en algunas de las categorías psicológicas y psicosociales que 
emanan del otro elemento del binomio que nos ocupa, LA PERSONA, la abordaremos más adelante.

Desde la Teoría Psicosocial del Origen de los Afectos:

Que un Objeto, entendido el concepto en toda su amplitud y sin referirnos en lo absoluto a la concepción psicoanalítica, nos produzca un efecto de Atracción: "tendencia al acercamiento", y Afecto: "mantenimiento del mismo" depende, en principio, de tres factores: la Proximidad, la Similaridad y la Eficacia.

Proximidad: si disfrutamos de más posibilidades de mantener el contacto con un "Objeto", es más probable que descubramos aspectos del mismo, asociados con otros que han despertado en nosotros actitudes (1) positivas, así como similaridades, salvo que se establezca una situación de reactancia o rivalidad.

Similaridad: Desde el punto de vista de la Psicología Social, no es cierto que "polos opuestos se atraen", aquello en lo que reconocemos algo de nosotros mismos tiende a atraernos.

Eficacia: Aquel objeto que nos resulta eficaz o con el que nos sentimos eficaces posee para nosotros una mayor capacidad de atracción.

Evidentemente, como ha demostrado hasta la saciedad el Conductismo, la experiencia vivida hace que aquellos objetos con los que se ha establecido una relación de afecto de valencia predominantemente positiva, den lugar en el sujeto a una actitud hacia ellos, o hacia otros que aquél perciba como similares en los aspectos significativos, de carácter positivo en mayor o menor grado.

J. Bleger define: "se llama aprendizaje o learning a este proceso por el cual la conducta (*) se modifica de manera estable a raiz de las experiencias del sujeto” (2) (1996:242).

Por último, y asumiendo los paradigmas del aprendizaje social, las personas no aprendemos solo de lo vivido y reforzado en nuestro propio e individual devenir, la percepción de los otros, de las consecuencias observadas o atribuidas de sus conductas, e incluso las reacciones emocionales de "los modelos", al subjetivizarse, pasan a formar parte de nuestro acervo experiencial. En nuestra cultura hay factores que, a una mayoría de personas, les despierta una apriorística actitud evaluativamente positiva, por ejemplo la belleza.

Desde estos planteamientos, y centrando nuestra reflexión en el objeto de este apartado: EL MÓVIL, podríamos plantearnos cuál/cuáles de estos factores

(1) Actitudes: “ Son asociaciones entre objetos actitudinales (prácticamente cualquier objeto del mundo social) y las evaluaciones de estos objetos” (Fazio,R.H y Roskos-Ewoldsen,1994, citados por Baron y Byrne, 1998:130).

Una vez establecida la relación de afecto, si sigue satisfaciendo las necesidades de los individuos implicados, esta relación tiende a mantenerse.

(2) Bleger entiende la "conducta" como una manifestación de lo que debe seguir siendo el objeto de la Psicología: la personalidad, que nunca puede ser entendida como una suma de conductas. 
puedan estar presentes o constituirse en variables, de mayor o menor entidad, influyentes en el crecimiento acelerado e intenso del número de móviles.

La Telefonía Móvil se ha extendido, en dirección centrífuga, del mundo político y económico-empresarial, al profesional y al familiar; como consecuencia, al menos por la proporción de géneros en dichas actividades, del mundo masculino al femenino, de los adultos a los jóvenes y, en número que deduzco insignificante, a los ancianos; de las grandes urbes al mundo rural y del norte al sur.

En mi opinión, la experiencia positiva anterior con otros instrumentos de comunicación interpersonal, y, sobre todo, valores ligados a la EFICACIA, son los factores más significativos en la "aproximación" al móvil de la avanzadilla de usuarios definida anteriormente(3). A estos factores se sumarán, posteriormente, los valores simbólicos (de estatus, poder, modernidad, etc.) y los mecanismos de aprendizaje social, haciendo que los círculos de población que "necesitan", "desean" y finalmente acceden al nuevo objeto de consumo, se hagan más y más amplios.

\section{La persona/la personalidad}

A las 7.30 a.m., llega la señora que realiza la limpieza en casa, trae su móvil, de tarjeta, solo para estar localizada por si sus hijos, de 10 y 13 años, la necesitan.

Prácticamente nunca llama ella, ¿no es suficiente el teléfono fijo para cubrir esa función?.

Cualquier calle. El mobiliario urbano se ha enriquecido con un nuevo conjunto ornamental formado por elementos individuales, estáticos y dinámicos, que se organizan y estructuran en múltiples combinaciones, aparentemente caprichosas: varón encorbatado, quieto, tenso, con una mano en un oído, el objeto que se supone sujeta es tan pequeño que apenas se ve, y la otra como taponando el otro; una chica camina relajadamente mientras mantiene el móvil, coloreado y claramente visible, casi pegado a su oreja; una señora busca con nerviosismo en su bolso, que emite una repetida e insistente musiquilla; algunos de los elementos del conjunto van en su automóvil, con la postura ya descrita y conduciendo con una sola mano.

Son las 10 de la mañana, en la cafetería desayunan personas de diversos grupos sociales, edades y condición. Con los ruidos y sonidos habituales se mezclan distintas y conocidas composiciones, timbres de variada intensidad y, prácticamente, todos los presentes buscan en algún rincón de su vestuario o miran al objeto situado encima de la barra o la mesa.

(3) Apuntamos la hipótesis de que es precisamente la experiencia de ineficacia de los ancianos frente a las nuevas tecnologías, más que factores económicos, lo que puede explicar el menor uso del móvil por este grupo de población. Personas mayores con una actividad intelectual, no responden a este perfil de uso. 
Con esta introducción observacional y descriptiva de escenas que, en mi opinión, son comunes y todos podríamos suscribir, pretendo mostrar, de forma suficientemente ilustrativa, la necesidad de abordar este apartado eligiendo como unidad de análisis, no la persona aislada, sino un "tipo genérico" humano, desde un paradigma muy cercano a la idea de "personalidad básica"(4) que surge, por los años treinta, dentro de "ciertos grupos de antropólogos, psicólogos y psicoanalistas”, como afirma H. Carpintero en su colaboración en el Tratado de Psicología Social de Baron y Byrne (1998:12): "La Psicología del Hombre Masa". Item más, desborda el propósito y extensión de este trabajo, el análisis exhaustivo de todos los extremos que abarca el plano psicológico del ser humano, aún considerándolo desde una perspectiva tipológica (5).

De hecho, lo que he descrito en la narración introductoria, no son personas ni personalidades, son CONDUCTAS, que en sentido estricto se referirían al conjunto de fenómenos que son observables o que son factibles de ser detectados, pero, como ya definí en el punto anterior, asumo el enfoque de J. Bleger: "el estudio de la conducta se hace en función de la personalidad y del inseparable contexto social, del cual el ser humano es siempre integrante; estudiamos la conducta en calidad de proceso y no como "cosa, es decir dinámicamente." (1996:27)

Partiendo de los conceptos definidos de Personalidad Base y Conducta, me sitúo, ante la unidad de análisis, como el fotógrafo ante el objetivo de la cámara, con la libertad de realizar su trabajo creativo eligiendo, para lograr la finalidad buscada, desde la panorámica más amplia hasta el detalle magnificado en un primer plano, desde la policromía del color al blanco y negro, desde el difuminado a la mayor definición de imagen.

Antes de comenzar la "sesión fotográfica", propiamente dicha, es necesario tener a punto todo el instrumental técnico y en nuestro oficio, esos instrumentos son las palabras y los conceptos, faltando aún por definir, específicamente, los que dan título a este punto del artículo.

En el lenguaje coloquial utilizamos con frecuencia las palabras Individuo, Persona, Personalidad; desde el punto de vista científico hay que definirlas desde un marco teórico concreto, y darles un nuevo contenido semántico, labor que entraña importantes dificultades, ya que no siempre se consigue un resultado operativo a la hora de escribir, explicar o predecir la conducta. Con la pretensión

(4) Carpintero define la Personalidad Básica, citando a Linton, como: "una configuración de personalidad compartida por el grueso de miembros de la sociedad como resultado de las experiencias tempranas que tienen en común"

(5) En cualquier sentido clasificatorio, basado en variables constitucionales, de personalidad, dinámicas o de la forma de ser hombre. 
de ser lo más clara y precisa posible en este punto, que solo pretende fijar los conceptos, adoptaré la sistematización y definiciones aportadas por E. Ibañez Guerra en el capítulo 7 del Tratado de Psicología General de J. Mayor, J.L. Pinillos, E. Ibañez y V. Pelechano (1989:241-263):

- Psicología del Individualismo: Aquella que tiene como objeto de estudio el INDIVIDUO(6). "Los distintos intentos por estudiar al individuo desde un punto de vista científico van desde las primeras teorías constitucionalistas y/o temperamentales hasta la actual Psicología del Individualismo, pasando por la psicología Individual de Adler. El eje a lo largo del cual podemos situar los distintos modelos teóricos va desde el individuo considerado como "sujeto empírico", hasta el individuo considerado como "valor" y, por tanto, como origen del hombre y del mundo social (individualismo)". (op. cit:248).

- Psicología de la Persona: Aquella que tiene como objeto de estudio a la PERSONA (7). A propósito de este concepto, E. Ibáñez afirma: "Aunque resulta artificial, preferimos distinguir entre Individuo y Persona porque desde nuestro punto de vista, la Psicología de la Persona entraña muchos más aspectos que la Psicología del Individuo". "Como señala Robinson (1982), el concepto de Persona hace referencia a una colección de atributos compartidas por entidades de un cierto tipo, atributos que no están presentes, al menos en el mismo grado en el reino animal. De este modo, encontramos que la Persona es realmente la base de una psicología de la Personalidad preocupada por los atributos -rasgos- que poseen las personas" (op. cit:254). La autora, siguiendo a Epstein, identifica, funcionalmente, el concepto de persona con el de self o propium, definido por Allport "como aquello que permite integrar los distintos rasgos y proporcionar un sentido de "unidad" interna, tanto del carácter biopsíquico de la persona como de su carácter social”.(op.cit:255).

- Psicología de la Personalidad: Aquella corriente psicológica que tiene como objeto de estudio la PERSONALIDAD(8). Los autores, al acercarse a este

(6) Individuo: En el Diccionario de María Moliner se define como "cada ser completo y separado, de una especie y género". Analizada le atribuye un carácter de singularidad: un solo ser completo, separado y en su totalidad; de cualquier especie: mineral, vegetal o animal. Como adjetivo se señala su cualidad de indivisibilidad.

(7) Persona: En el Diccionario de María Moliner se define como "individuo de la especie humana”. Etimológicamente, la palabra Persona viene del latín personare (máscara) y como plantea E. Ibañez "ya Cicerón señala que la palabra hace referencia a cuatro aspectos distintivos del ser humano: a) su apariencia externa; b) el papel social que uno debe desempeñar; c) la dignidad o estatus social y d) el conjunto de cualidades que hacen a un ser humano apto para el trabajo que debe realizar. Como puede verse, el concepto de persona parece relacionar al sujeto con el medio social donde se desenvuelve"(op.cit:247). Realmente hablar de una Psicología de la Persona es una redundancia porque aquella es, por definición, el objeto de estudio de la Psicología, pero, la autora citada, la introduce para profundizar en el abordaje unitario del ser humano y para diferenciar Persona y Personalidad.

(8) Personalidad: Hay tantas definiciones como escuelas psicológica e incluso como autores. Para Ibañez, basándose en el análisis de la definición/es del diccionario: "la personalidad es aquello que convierte a un sujeto en único e irrepetible y a su vez lo que permite distinguirle de los demás”. 
concepto, elaboran modelos generales de cómo se organizan, estructuran, se forman o actúan los elementos que la componen, pero, en sentido estricto, los Psicólogos de la Personalidad, a pesar de que este concepto no es asimilable a diferencias individuales, han conseguido sus mayores éxitos gracias a ellas: "los análisis experimentales pronto preocuparon a los personólogos, que encontraron en el concepto de Dimensión la manera de explicarla e, incluso, de predecirla y reducirla. De este modo, la Personalidad, encontró pronto en la correlación y en el análisis factorial su propia metodología de estudio, lo que la convirtió en una ciencia más entre las ciencias psicológicas”.(op. cit:260).

En conclusión del Concepto más globalizador, el INDIVIDUO, pasamos al individuo de la especie humana, la PERSONA, para concretar con el concepto de PERSONALIDAD, los aspectos psíquicos del sujeto.

Por tanto, creo queda suficientemente justificada mi elección del segundo concepto, la PERSONA y el de Personalidad pero adjetivada: la PERSONALIDAD BASE, lo que las personas pertenecientes a un mismo grupo social tienen en común por desarrollarse en un determinado contexto histórico y cultural, donde se manifiestan y se observan sus CONDUCTAS.

\section{Móvil-persona: el contexto}

Antes de continuar, dos palabras sobre el contexto ya que, retomando la metáfora del fotógrafo, ese contexto sería el paisaje elegido, al que nos acercamos en un momento determinado y por el que transitan los dos elementos objetos del análisis. Es el escenario que, no sólo cobija el encuentro, sino que lo influye y hasta cierto punto lo provoca y determina.

J. Bleger, en su obra Psicología de la Conducta afirma: "Para estudiar un fenómeno debemos hacerlo en función de sus relaciones en un momento dado"... "Las cualidades de un ser humano derivan siempre de su relación con el conjunto de condiciones totales y reales. El conjunto de elementos, hechos, relaciones y condiciones, constituye lo que se denomina SITUACIÓN, que cubre siempre una fase o un cierto periodo de tiempo" (1996:40).

Estamos en el periodo de transición entre dos siglos y dos milenios, con un tipo humano producto de la cultura occidental moderna, concretamente del S. XX, siendo los sistemas educativos y las circunstancias sociales y técnicas los factores más decisivos en su aparición. H. Carpintero identifica a este tipo humano con el hombre-masa de Ortega, y siguiendo a este autor lo describe: "Lo que lo caracteriza es que reclama con insistencia los placeres; cree tener derechos pero no obligaciones; al actuar, impone su voluntad con violencia de modo que esta es ya, en rigor su "única razón”... "desea el automóvil y goza de él, pero cree que es una fruta espontánea de un árbol edénico" (op. cit:13).

La situación es un marco, un paisaje, demasiado amplio, por ello es necesario otros "encuadres", que permitan reducir la panorámica y ganar en 
precisión, para ello se requiere enfocar el CAMPO, que no sería más que el conjunto de elementos coexistentes e interactuantes en un momento dado, es decir el resultado de realizar un corte hipotético y transversal de la situación delimitando en el espacio y el tiempo el fenómeno que se estudia. El campo concreto de mi análisis está explicitado en la introducción, así como los distintos ÁMBITOS (9) que irá recorriendo la cámara. Es decir, utilizaré un encuadre situacional, ahistórico o sistemático.

\section{Móvil-persona. interactuación y motivación social}

Hace poco más de un lustro se podían escuchar las siguientes frases: "Sr. B. Le vamos a proporcionar un teléfono móvil para que podamos estar en contacto cuando esté fuera de la oficina". "Mi empresa no me proporciona el móvil, pero voy a tener que comprármelo para poder tener mayor libertad de movimientos". "María, mira lo que me he comprado, es lo último de lo último". Hace 4 o 5 años: "Mi jefe me tiene loco, me llama al móvil a cualquier hora, es un poco caro pero no he podido resistirme”. " $A$ Ah! Pero ¿Tu empresa no te proporciona el móvil?". "Pepela no voy/vamos a tener más remedio que comprarme/nos un móvil, así estaremos más localizados si los niños me/nos necesita/n”. "Me resisto a tener que comprarme ese cacharro". "Papi, a Marta le han comprado un móvil y sus padres están encantados porque así la llaman desde el barco". Actualmente: "El niño ha cumplido 14 años y tendremos que comprarle el móvil" "Felipe enséñame tu móvil, es aún más pequeño que el mío, qué cobertura tiene".

"Te daré los números de mis dos móviles". La misma evolución podría observarse si se analiza la evolución de la publicidad.

Aunque, evidentemente, en toda relación humana está implícita la comunicación, que trataré más adelante con toda amplitud ya que es el fenómeno nuclear del tema que nos ocupa, en este apartado trataré de la MOTIVACIÓN para interactuar, ya que INTERACTUACIÓN, es un concepto mucho más amplio que COMUNICACIÓN y, por otra parte, quiero referirme, específicamente, a la interactuación entre los dos elementos de nuestro binomio Móvil-Persona, y difícilmente podría hablarse en este caso de comunicación.

Para interactuar, es imprescindible entrar en contacto. ¿Por qué? ¿Para qué? ¿Cómo? Dirijamos el objetivo de la cámara a nuestros "personajes".

Ya he tratado de las fuerzas que están en la base de la atracción y el acercamiento. En esos fenómenos es, la cualidad del "objeto" -del móvil- para el sujeto, lo que pone en marcha esos tipos de experiencias y conductas consecuen-

(9) Ámbito: La delimitación de la amplitud del Campo, define los diversos ámbitos (social, institucional, de interacción, conductual, individual, etc.) 
tes; cuando son necesidades del sujeto los que ponen en marcha aquéllas, se habla de MOTIVACIÓN(10), enfoco, por tanto, al "sujeto", a la Persona.

En el T. I del Tratado de Ciencias Psicosociales Aplicadas, coordinado por Latorre Postigo se encuentra la siguiente puntualización en lo referente a la definición de Motivación: Dado que no existe una definición consensuada se puede describir la conducta motivada en función de sus características distintivas:

- Es propositiva: está orientada y dirigida hacia una meta que el organismo intenta alcanzar.

- Es fuerte y persistente: los organismos emplean grandes cantidades de energía para conseguir la meta y superar los obstáculos.

- Es periódica: muchas de las conductas motivadas se repiten en el tiempo.

Las conductas de comprar, pedir y usar el móvil, ¿son conductas motivadas? ¿Qué podemos decir, de forma más específica, no solo sobre esta motivación en concreto, sino también sobre si ha sufrido algún tipo de evolución o modificación, desde los primeros momentos hasta la actualidad?

Parto de la premisa de que, al nacer la Telefonía Móvil, ya, la absoluta mayoría, se podría decir que la totalidad de la población del mundo occidental, consideraba el teléfono como un objeto imprescindible, y la comunicación telefónica había sustituido, en una proporción muy significativa y con efectos trascendentes sobre las pautas culturales, al contacto personal, tanto en el ámbito laboral como en el familiar y social.

Por tanto, "en el principio" del móvil ya existía la necesidad del teléfono y éste ya condicionaba el estilo de vida; estaba presente en los hogares, en los locales públicos, en los centros laborales y en las calles (los que formaban parte del mobiliario urbano, fijos y públicos); a veces se buscaba febrilmente una cabina telefónica o se hacían largas colas ante ellas, aunque aparentemente, no constituía un desideratum poder hablar en cualquier momento y desde cualquier lugar; pero, al surgir la posibilidad de hacerlo en la calle, en el coche, sin colas, sin molestias, privadamente, el "hedonista" y "operativo" sujeto de la Era de la Comunicación, tardó poco en pasar, ante la oferta de la nueva tecnología, de un "no sé" dubitativo y curioso a un "tengo que", sintiéndose impelido a poseerlo para cubrir una gama cada vez más amplia y variada de necesidades.

(10) El término Motivación supone un estado de estimulación interna que resulta de una necesidad y que generalmente activa la conducta orientada a satisfacerla, por tanto este concepto lleva implícitos dos componentes uno que proporciona energía al comportamiento y otro que lo dirige. La necesidad hace referencia a la experiencia física y/o psicológica y social de déficit. 
Aceptando que las conductas de comprar, pedir y usar el móvil, son conductas motivadas, iré un poco más lejos en el análisis. ¿Existen tipos de motivación? ¿De qué tipos estamos hablando?

Los motivos se clasifican en primarios o biológicos y secundarios o sociales. La conducta que analizamos tendría una base motivacional del segundo tipo, ya que las motivaciones biológicas, según Madsen, tienen las siguientes características: Una base orgánica, determinan actos universales de conducta, están determinados por señales innatas y el organismo tiene que satisfacerlas para conservar la salud y la vida. Evidentemente la necesidad del móvil no llega a tanto.

¿Qué define los motivos secundarios o motivaciones sociales? Recurrimos de nuevo al Tratado de Latorre: "Las necesidades sociales son aprendidas y están determinadas por el ambiente social en el que se mueve el individuo... lo que nos da a entender la importancia de los mecanismos incentivos en su funcionamiento" (op.cit:341).

Los motivos biológicos (hambre, sed, sueño) son muy claros y definidos, aunque en la actualidad las conductas sexuales y las agresivas suscitan un importante debate, pero ¿Cuáles son las motivaciones sociales? La relación de las mismas y la teoría sobre sus bases, varía según los autores que se consulten, pero las que han generado un mayor número de trabajos empíricos, según Latorre, son:

A) Necesidad de logro: afán competitivo con una norma de excelencia.

B) Afiliación: Tendencia que tenemos todos los seres humanos a asociarnos con otros, a buscar contacto social esporádico o permanente, y a formar grupos.

C) Dependencia (11)

D) Aprobación: Se realizó un estudio en el que se concluía que muchas personas tienen tendencia a dar las respuestas socialmente deseables.... Las personas con gran necesidad de aprobación dependen de la evaluación favorable de los demás y eluden toda autocrítica. El motivo de la aprobación es en sí mismo el deseo de un apoyo social, autoprotección y evitación del fracaso. Sus objetivos incluyen el reconocimiento y el estatus social, protección y dependencia, amor y afecto" (op. cit: 344)

La lista es aún, en mi opinión, muy insuficiente y poco precisa aunque la complementemos con la Pirámide de Necesidades de Maslow, que incluye entre otras: necesidades de seguridad (salud, abrigo, comodidad); de afecto y pertenencia (se corresponderían con las de afiliación ya referidas); de autoestima (sentimiento positivo hacia uno mismo); de actualización (todos los comportamientos

(11) La conducta que produce la ayuda, atención, contacto físico, etc., de los demás. Su estatus de motivo nunca ha quedado bien establecido, entendiéndose más como una conducta reforzada en el proceso de aprendizaje. 
orientados a desarrollar todas las potencialidades propias y alcanzar el máximo rendimiento).

Desglosando cada uno de estos grupos de motivaciones y siguiendo este modelo teórico, vemos que se encuentran incluidas las que surgen de la búsqueda de experiencias de libertad, poder, individualidad, e incluso las que emanan de necesidades disfuncionales o patológicas.

Enfoquemos el Móvil como Motivador Social:

\subsection{Móvil y Necesidad de Logro.}

"Sta. llámeme al móvil si termina el presupuesto". "Voy por la autopista, no te localizaba. Las llaves las he dejado en...”.

Tanto en el mundo laboral como social, el móvil, como antaño lo fue el teléfono fijo, supone una mayor operatividad, potencia las capacidades de ser eficaz y controlar las posibles eventualidades.

\subsection{Móvil y Afiliación.} pts."

Oferta la publicidad: "Conéctate con los amigos que tu elijas por solo $\mathrm{x}$

Quedan los amigos: “Avisa a todos que estamos en la discoteca M".

Contacta la familia: "Hermana, estoy de compras, en tu casa me han comentado que tú también. ¿Nos vemos para tomar un café?

El móvil continúa la tradición del teléfono clásico en su facilitación de los contactos sociales y en el mantenimiento de las relaciones, compensando, en parte y en algún aspecto, las dificultades que las distancias, la movilidad y la premura suponen para las mismas.

\subsection{Móvil y Dependencia.}

Aún admitiendo que las conductas de dependencia no son, en sentido estricto, conductas motivadas sino reforzadas, utilizo este parámetro del paradigma elegido para introducir la diferenciación entre los extremos "sanos" y "patológicos" del continuum de actitudes que se manifiestan en un tipo de conductas. En este caso concreto, analizaré el uso del móvil en relación con el vector actitudinal que va desde la Dependencia Disfuncional(12) a la Independencia o Autono-

(12) Siguiendo la conceptualización de Dependencia como búsqueda de ayuda, atención, etc., considero Disfuncional, aquella que pone en marcha conductas desajustadas, cuantitativa o cualitativamente, que no permiten resolver y desenvolverse con eficacia existencial al sujeto en función de su edad y situación, que está en relación con variables de otra esfera experiencial (poder, dominancia, etc.) o con parámetros psicopatológicos. 
mía(13), que considero incluida, si es la adecuada para el periodo evolutivo y situación existencial en que se encuentra el individuo, en las Necesidades de Actualización de Maslow.

\subsubsection{Móvil y Dependencia Disfuncional.}

"Pepe, no se te ocurra cerrar el móvil por si tengo que llamarte, ya sabes lo que me asusto si creo que no puedo localizarte". "Hijo, ¡Cómo que no puedes dejar la clase para llevarme en coche!. Para eso te he comprado el móvil, para tenerte localizado".

"Papá, que me entra la angustia, si te tienes que ir, llévate el móvil y dime siempre donde estás”. “Cómo has llamado a tu suegra y no a tu madre cuando has llegado a la playa?

El teléfono en general ha supuesto, y el móvil en particular ha incrementado, la posibilidad de que las personas, excesiva, desviada o patológicamente dependientes, satisfagan sus necesidades disfuncionales de control del "otro". Se han constituido en "trampas" para que, en muchas ocasiones, el sujeto elegido para suplir las insuficiencias se sienta "obligado" (ya que le sentencian: "no te cuesta ningún trabajo"), a responder a las demandas, a pesar de su irritación o resistencia interna. En este sentido, la comunicación telefónica, viene a realizar una función vicariante del aislamiento, individualismo y alejamiento interpersonal (físico y psicológico) de la sociedad actual en el primer mundo.

\subsubsection{Móvil e Independencia o Autonomía.}

"Me encanta viajar solalo de noche, ahora, con el móvil, puedo hacerlo mucho más tranquila/o". "Dejemos a los niños en casa, si necesitan algo que nos llamen". Mientras tú haces eso, yo hago aquello, cuando termines me das un "movilazo".

Es bastante evidente que la telefonía móvil permite o facilita un mayor grado de elección de conductas alternativas y como consecuencia del ejercicio de la libertad individual y de la autonomía.

\section{4.- Móvil y Aprobación}

"Dame tu número de móvil. ¡Cómo! ¿Qué no tienes?". "Papálmamá, necesito el móvil, todos mis amigos lo tienen”. “ ¡Oh!, que chuli es tu móvil, me encanta el color, es ideal".

(13) Independencia o Autonomía: La actitud de afrontar y resolver de acuerdo con la edad y circunstancias. Búsqueda de ayuda y atención adecuada cuantitativa y cualitativamente. Experiencias positivas de libertad para desarrollar todas las potencialidades propias y alcanzar el máximo rendimiento. 
¿Se puede afirmar que la estructura social actual, considera deseable tener un teléfono móvil y refuerza positivamente utilizarlo? Creo que la respuesta es inequívocamente SI, tanto directamente, como a través de los modelos y la publicidad.

\section{5.- Nota final. Evolución de la Motivación}

En mi opinión, estas motivaciones se han ido intensificando, desde el nacimiento de la telefonía, en función del mejor conocimiento del manejo del objeto, de la mejora de las prestaciones ofertadas y del número de usuarios. Todo esto a sabiendas de que he obviado el proceso de influencia que el mercado ejerce, utilizando precisamente estos conocimientos, para incrementar la necesidad, reforzar actitudes positivas, dotar al objeto de valores de atracción y como consecuencia de todo ello, fomentar el consumo.

\section{6.- Móvil y comunicación}

En este apartado la diada primigenia se transforma, ante el objetivo de la cámara virtual de la que me he servido a lo largo del trabajo, en un sistema de cinco elementos: Emisor, Receptor, Canal, Mensaje y Feed-Back, es decir, un proceso de comunicación interpersonal a través de un canal concreto: el teléfono móvil.

Las modificaciones que las características de este nuevo canal han introducido en la comunicación, o incluso, ampliando la panorámica, el móvil como indicio a interpretar en la percepción del otro, y de la propia identidad, en resumen, en la Comunicación Verbal y No Verbal, serán el nuevo objeto de análisis.

M. Argyle en su obra Psicología del Comportamiento Interpersonal, incluye todas las conductas comunicativas dentro los Comportamientos Sociales que buscan la interacción, cuyo objetivo último sería buscar las respuestas deseadas de los demás: "Tales técnicas y signos comprenden una amplia gama de niveles de comunicación: desde los tipos de contacto corporal a los gestos y los modos de hablar"... "Además, estos elementos del comportamiento verbal y no verbal llegan a integrarse en estilos generales de comportamiento tales como los utilizados para establecer intimidad o dominancia"... "Aunque el principal fin de las técnicas sociales es provocar la respuesta de otros, parte del comportamiento social se ocupa simplemente de mantener el flujo de la interacción” (1994:37).

Es decir todo comportamiento social observable es COMUNICATIVO.

\section{1.- Comunicación Verbal.}

Para comenzar, un dato recogido por la edición digital de El Mundo de fecha 3 de noviembre de 2000 en su sección SOCIEDAD, proporcionado por una encuesta del CIS sobre el uso del ordenador y el teléfono móvil: "El 42,3\% de los 
españoles posee teléfono móvil. $Y$, de ellos, el 78,1\% dice que lo emplea "para conversar con amigos y familiares". Solo el 34,8 \% lo hace por trabajo"(14).

El lenguaje se utiliza para preguntar, informar, dar instrucciones u órdenes, influir, etc., pero Argyle afirma: "Una gran parte del lenguaje no tiene como objeto primario el comunicar alguna cosa seria o resolver algún problema. El lenguaje informal, como se le llama, se ocupa más del establecimiento, mantenimiento y disfrute de las relaciones sociales: la charla, el chisme ocioso... Se ha demostrado que aproximadamente la mitad de las costosas conversaciones a través del teléfono trasatlántico son de este tipo”. (op. cit.:46).

Dentro de la Comunicación Verbal, el móvil es uno de los elementos de las nuevas tecnologías que introducen la posibilidad de elegir entre dos modalidades de lenguaje: Oral y Escrito (la transmisión de la imagen aún no se ha popularizado ni se desarrolla, prioritariamente, en la Telefonía Móvil).

\subsection{1.- Comunicación Oral}

"Te cuelgo que estoy llamando desde el móvil" "Que ruido se escucha ¿Estas en un bar?... No, es la T.V.”

En mi opinión, la comunicación oral a través del móvil no introduce diferencias significativas, ni en lo linguiístico ni en lo paralingüístico, respecto a la comunicación a través de la telefonía fija; sólo, como se infiere de los ejemplos que preceden, en dos aspectos: uno es en la extensión del mensaje (más breve)(15) y por tanto en el contenido de la mayoría de las llamadas, que, en principio, depende de la situación económica del usuario y de si lo paga alguna institución o empresa; evidentemente, si el usuario no es el que asume el coste ni lo realiza a cargo de una actividad laboral, es decir, es dependiente, el control externo es más restrictivo; en segundo lugar, las posibilidades de "adecuar" la información a lo más "conveniente", sobre todo en lo que se refiere al lugar donde se encuentran los sujetos, son mucho más amplias.

\subsection{2.- Comunicación Escrita. Los Mensajes}

Para ilustrar este apartado, utilizaré la transcripción, cuasi literal, de algunos párrafos de un artículo de El Mundo Digital de 16 de febrero de 2000 en su sección SOCIEDAD, titulado “La jerga móvil se impone en las aulas”, ya que, solo su lectura, hace baladí explicitar lo que tan gráficamente en él se plasma.

(14) Dado que tal y como está recogida la información, no se puede conocer la muestra ni la metodología de la encuesta, y que, conectando directamente con la base de datos del CIS, no consta el trabajo al que hace referencia el artículo, renuncio a realizar hipótesis sobre la base de este porcentaje, en relación con el fín de la conducta comunicativa.

(15) No me refiero, en principio, a breve en el sentido de conciso, que transmite una amplia información de forma clara, sino más bien de leguaje telegráfico o autolimitado. 
Subtitula el autor: "Los adolescentes crean un nuevo lenguaje ideado para economizar sus mensajes telefónicos”.

Desarrolla en el texto: "Madrid.- “Bip-Bip”. Ana de 18 años, cierra su cuaderno de literatura y deja su comida rápida. "Hola. Stoy studiando mil” reza el móvil en su pantalla, tan pequeña como una nota plegada y pasada dentro de un aula. "Hoy $m$ tok el tema 3. Stas en la biblio?" "No toy en el McDonals".

Esta peculiar forma de lenguaje se desarrolló por la necesidad económica (si el chisme celular se puede considerar una necesidad); una llamada móvil cuesta hasta 190 pts. el minuto; un mensaje 20 pts. en total. Pero hay un problema ¿cómo resumir toda la angustia y el hastío de la adolescencia en tan solo 160 caracteres, el máximo permitido para un mensaje?

Así que los jóvenes inventaron rápidamente un sistema de abreviaturas, ortografía creativa y dibujos, todos + o - (más o menos) inteligibles en cualquier región.

"Aquel estallido de pasión lingüística, sin embargo, no ha logrado seducir a los profesores de los institutos, donde el mensaje móvil se ha convertido en la forma predilecta de quedar con los amigos y pasar notas durante la clase. De ahí las peticiones de padres y profesores de que se regule el uso del juguete más popular de estas Navidades".

Todavía no existe un libro de texto, pero según algunos alumnos del Colegio Claret y el Instituto San Juan Bautista en Madrid, los 10 mandamientos de la Ley del Móvil son:

1) Quitarás la primera " $e$ " y la primera " $h$ ” cuando te dé la gana.

2) Evitarás las vocales siempre que no confundan el sentido

3) Usarás cifras o símbolos matemáticos si es posible. Salu2

4) Recurrirás a las abreviaturas inglesas si son más económicas. O.K.

5) Olvidarás el primer signo de interrogación.

6) El sexto no acentuarás.

7) No desearás las mayúsculas.

8) Sustituirás la sílaba “ca” por la letra $k$

9) Abreviarás frases comunes: En vez de me despido, "md".

10) Despreciarás los pronombres me y te. Bastará que uses " $m$ " y " $t$ ".

Al final del artículo reproducido, una estudiante de Filología Hispánica vierte la opinión de que este tipo de práctica no es alarmante ni negativo; yo me permito disentir de una aseveración tan categórica. Otro fenómeno actual, la reducción del vocabulario juvenil, su simplificación y la influencia del inglés, no digo que sea determinante, pero sí está relacionado con un empobrecimiento en los procesos del pensamiento, ya que lenguaje y pensamiento son dos funciones psíquicas íntimamente relacionadas, y este lenguaje escrito es aún más empobrecedor. Por otra parte, a un individuo que domina perfectamente la ortografía, como 
sería el caso de la estudiante del artículo, no es fácil que se le confunda, pero a un chico de instituto, ya bastante poco exigido y formado en este tema, es muy posible que esta práctica le aleje de una suficiente corrección en el uso del lenguaje escrito.

Curiosamente, aunque la ventaja económica de los mensajes es independiente de la edad del usuario, se utiliza de forma abrumadoramente mayoritaria por la población juvenil, convirtiéndose en una seña de identidad, en un componente de la cultura de ese grupo de población.

\section{2.- Comunicación No verbal}

La comunicación a distancia, a través de cualquier tecnología, suprime o elimina la mayoría de los comportamientos comunicativos No Verbales: táctiles, proxémicos, de elementos provenientes del S.N.V., olfativos, posturales, ademanes, expresión facial, etc, pero, por otra parte, introduce, según se juegue con una serie de variables, unos nuevos signos que se traducen en mensajes más o menos ambiguos, pero con un significativo valor comunicacional, y que son compartidos por un amplio grupo de población, es decir van formando parte de las pautas culturales.

Desarrollo este apartado desde un paradigma semiótico (16). Las conductas comunicativas no verbales relacionadas con el uso del teléfono en general y el móvil, en particular, las conceptualizo como signos, a partir de los cuales inferiré diagnósticos de pautas de interactuación y valores comunicativos y relacionales. En parte, estos signos son comunes a la telefonía fija y móvil, pero incidiré, fundamentalmente, en aquellos más específicos de nuestro protagonista: el Móvil.

Dada la naturaleza del objeto de estudio y del paradigma utilizado, opino que la metodología expositiva más adecuada para este punto es la enciclopédica, con la licencia de no seguir una ordenación alfabética, imposible por no tratarse de signos lingüísticos.

Dividiré este breve y humilde intento de establecer el inicio de una Semiótica del Móvil, en dos listados de "signos" según el estado funcional del teléfono: ABIERTO Y CERRADO, para el móvil(17), COLGADO O COMUNICANDO,

(16) Define el Diccionario Enciclopédico Salvat: “SEMILOGÍA (Del gr. semelon, signo, y logos, tratado) $f$. Semiótica. SEMIÓTICA (del gr. semeiotike, sobreentendiendo y techne, arte) f. Parte de la medicina que trata de los signos de las enfermedades desde el punto de vista del diagnóstico y el pronóstico.". Y en el Espasa. "SEMIOLOGÍA: Estudio de los signos de la vida social. SEMIÓTICA: ling. Término propuesto por F. De Saussure para designar la ciencia que se ocuparía de la vida de los signos en una comunidad, y de la que formaría parte la lingüística.”.

(17).- En la relación, cuando el signo y su posible significado se refiera al móvil, aparecerá una "m", y una "f" si se refiere al fijo; cuando sea común a ambos aparecerá como "m.f". 
para el fijo.(18). Igualmente diferenciaré, en algunos casos, entre El rol de Emisor(E) o Receptor®

Antes de abordar la descripción de los signos, dos palabras sobre algunos aspectos técnicos, que son de sobra conocidos por todos, pero que introducen matices esenciales en las conductas que vamos a describir e interpretar.

1) Los teléfonos fijos, la mayoría de ellos en la actualidad, no muestran en pantalla el $\mathrm{n}^{\mathrm{o}}$ del emisor, los móviles, todos, no sólo muestran el $\mathrm{n}^{\mathrm{o}}$, sino que, si está incluido en al agenda de la unidad telefónica, aparece su nombre.

2) Hasta ahora, los fijos no informaban de los números de las llamadas no atendidas salvo que hubiesen dejado un mensaje; los móviles te informan de las llamadas perdidas tanto si han dejado mensaje como si no.

3) Los fijos no tienen una información específica de desconexión.

4) Salvo a través del fax, el fijo no emite mensajes escritos, y desde luego la cualidad de intimidad de estos, es infinitamente menor que el escrito que aparece en la pantalla del móvil.

5) Los fijos no llevan agenda incorporada, ni avisador personalizado (sonoro o no).

6) Los fijos no forman parte de nuestro atuendo ni lo condicionan.

7) Los fijos no producen más que una mínima interactuación en lugares públicos.

8) Las unidades fijas, en nuestro medio socio-cultural, son absolutamente populares y salvo que incorporen últimas y sofisticadas tecnologías, no suponen, per sé, un valor de estatus.

Como se deduce de esta breve relación, la telefonía fija interactúa con la móvil, incorporando aquélla prestaciones de ésta que se valoran como demandadas, y desarrollándose ésta gracias a la tecnología de su predecesora. Por ello muchos de los signos que incluiremos serán comunes y quizás cada vez más.

\section{Semiótica de la comunicación telefónica}

\section{PARTE I.- TELÉFONO ABIERTO}

$\mathrm{N}^{\mathrm{o}}$ de Llamadas (m.f)(E.R): De forma absoluta, no es significativo, depende de múltiples variables. Un $n^{o}$ de llamadas muy elevado, respecto a la media de otras personas de características similares, podría interpretarse, fácilmente, como un sujeto con un alto nivel de estrés.

(18).- En el fijo, nunca se da la eventualidad de estar desconectado, por ello solo puede estar abierto, libre o comunicando. 
$\mathrm{N}^{\mathrm{o}}$ de llamadas por intervalo de tiempo (m.f). (R): La variación significativa de la frecuencia de llamadas por un espacio mantenido de tiempo, siempre tiene un significante; si es en sentido decreciente: mayor aislamiento, pérdida de poder, disminución en la actividad empresarial, cambio de situación, residencia, actividad, etc. Y VICEVERSA.

(E): La variación significativa en sentido decreciente: necesidad de aislamiento y/o concentración, bajada del estado de ánimo, pérdida de poder económico, rupturas, estrés, enfermedad, etc. Y VICEVERSA

Conocer el $\mathrm{n}^{\mathrm{o}}$ de teléfono: (f): No tiene mayor valor, se puede conseguir con bastante facilidad. Más significativo es la ocultación en las guías, figurando a nombre de un tercero: personas celosas de su intimidad por motivos legítimos o ilegítimos.

(m): Dar el $n^{o}$ de tu móvil o conocer el de otro, supone un nivel de interés (puede ser circunstancial por requerirlo una actividad concreta y limitada en el tiempo) y/ o confianza.

Los números que se conocen de memoria(m.f): Salvo casos donde la persona valora, como un reto personal o como demostración de poseer una memoria sobresaliente, el recordar el mayor número posible de teléfonos, puede significar: interacción cercana e intensa, en caso de que no exista, interés preferencial.

Números que se mantienen en la agenda o que se temen perder (m.f.). (E): Personas a la que atribuyes un interés o eficacia y con la que supones puedes desear contar.

(R): El número de personas que tengan tu teléfono en "favoritos", puede ser una medida de tu eficacia y sociabilidad. Importa matizar en ambos casos el aspecto cualitativo de dicho grupo de población.

No llama alguien que se espera y está en la agenda(m.f). (R): Si se mantiene la situación por un tiempo suficientemente significativo, su nivel de interés por la interactuación es diferente (menor), o utiliza una estrategia de poder. Si se ha llamado varias veces esa interpretación tiene más probabilidades de no ser interferida por otras variables y mucho más si esta secuencia conductual, se produce a través del móvil, ya que las llamadas quedan recogidas. (19). No llamas a alguien que sabes necesita o desea esa llamada (E): Evitación de una tensión, conflicto, experiencia de ineficacia o daño supuesto al otro. Agresividad. Defensa de la autoestima.

Teléfono operativo en situación de entrevista cara a cara (m.f.): (R): Si no se advierte de que se espera una llamada concreta, necesidad o ansiedad de/por estar localizado/a, falta de respeto al interlocutor o al tema, estrés; en el caso de que sea el móvil, también podría significar ocultamiento de la actividad. (E): Si

(19): Hay una canción del grupo Azucar Moreno que plasma esta situación "Mi móvil encendido nunca te ha identificado". 
se interrumpe una conversación para llamar e igualmente no se ha advertido de la necesidad de hacerlo, los significantes serían los mismos que los ya explicitados, pero la irritabilidad del interlocutor puede ser más intensa, ya que no existe la atenuante de la irresponsabilidad.

En general, la actitud social manifestada, para estos comportamientos, es bastante permisiva y tolerante.

Móvil abierto en evento social (concierto, conferencia, clase, entierro, boda, etc.) (m):

Falta de atención (despiste), respeto, interés, educación; agresividad encubierta; individualismo exacerbado.

Llamada y corte antes de ser recogida (f.m): (R.E): Si es conocido por ambos, emisor y receptor, el significado, es una forma de comunicación pactada con un significado concreto: "llamaré" "llámame" "me acuerdo de ti" "hay moros en la costa".

(R) Si no se espera y es en el fijo (sin pantalla), no tiene un significado concreto aunque puede producir: incertidumbre, inseguridad, indiferencia, irritación, curiosidad. Si es en el móvil, al conocer el $n^{o}$ se disuelve la incertidumbre y puede tener un significado más concreto: "no tiene dinero y prefiere que lo llame", "no sabe si puedo hablar en este momento".

No se responde a la llamada (m.f): En este caso es siempre un signo para el emisor: si es fijo, no está (puede incluso levantar una alarma si se trata de niños o personas mayores).

Si es móvil, puede ser que esté fuera de cobertura, no le ha dado tiempo, lo tiene apagado..., sólo si se repite la conducta y se tiene constancia del conocimiento del receptor de que se ha producido la llamada, el significado puede variar y traducirse como una negación a interactuar con nosotros, lo que ya analizamos en un punto y ampliaremos al referirnos en el siguiente apartado al móvil apagado.

\section{Móvil apagado}

En sí, el teléfono apagado, si no responde a una eventualidad funcional sino intencional, tiene el mismo significante que el SILENCIO, no es que tenga el mismo significante, es que es SILENCIO, no el silencio como parte del sistema que denominamos leguaje verbal, sino el silencio conductual; Castilla del Pino en su artículo "El silencio en el proceso comunicacional" que aparece en su libro recopilatorio El silencio ya diferencia: " $Y$ cuando no hacemos señas ¿qué hacemos?. Hacemos señas también; señalamos con nuestro silencio, que en el nivel no verbal es, no el reposo, sino la quietud. El silencio por antonomasia (el silencio verbal) y la quietud (silencio extraverbal) son, pues, formas de conducta, formas de habla: en suma, actuaciones" (1992:80) 
El SILENCIO como signo, en palabras de J.L. Ramirez Gonzalez,: “Equivale a considerarlo como algo dotado de sentido y, por tanto, portador de esa estructura de significante y significado que va asociada al nombre de Saussure" (op.cit:15)

Este mismo autor nos lleva al núcleo mismo de nuestro análisis, al diferenciar el Silencio de LOS SILENCIOS: "Voy a desarrollar mi consideración del silencio dentro de tres esferas de sentido.

Resumiendo: 1. El Silencio (acepción metafórica)

2. Los silencios.

a) como hecho social (acepción primaria)

b) como lo tácito en el decir (acepción metonímica)” (op.cit:21).

Siguiendo estos planteamientos conceptuales. El apagar el móvil es un silencio extraverbal en la esfera de sentido de los hechos sociales.

Una vez definido el Silencio, los Silencios, ¿Qué podemos decir de su semiótica? ¿Qué comunica/n?

En el recopilatorio ya citado y que recomiendo, encontramos las respuestas posibles, totalmente aplicables al silencio concreto del Móvil Desconectado.

El máximo poder del silencio es su ambigüedad, dice Castilla del Pino: "más que ningún otro el significado del silencio es ambiguo, porque la mayoría de las veces el silencio se prolonga, es decir, se guarda silencio sobre (el motivo de) el silencio, no se explica el por qué del silencio. De aquí la frecuencia con la que el silencio se torna inquietante, suscita desasosiego, angustia -la angustia de no saber, de la imprecisión, de la ambigüedad-" (op.cit:83).

Desde el punto de vista fenomenológico, lo que significa el silencio concreto solo lo sabe el que calla, el interlocutor se obliga a barajar múltiples posibilidades, luego tendrá que preguntarse no por el significado sino por el uso del silencio en una situación determinada, ya que el emisor solo deja ver los significantes, desde esta perspectiva sería más válido preguntarnos ¿Cómo usamos nuestros silencios? que ¿Qué quiere decir con su silencio ese que calla ante mi? Pero desde el concepto de personalidad base nos valdría el uso del silencio y el significado otorgado al mismo por una cultura determinada en determinados ámbitos y tipos de relación.

Define Castilla: "El silencio, como la mayoría de los signos es polisémico y posee una función ilocutiva porque obedece a una intención y una función perlocutiva, porque con él pretendemos producir determinados efectos"... "Con el silencio, otorgamos, reprobamos, humillamos o nos humillamos, acusamos o nos acusamos; y también nos desentendemos, o hacemos como que nos desentendemos o ironizamos" (op.cit.:83). 
Desde este análisis, en la conducta de apagar el móvil intencionalmente, y despreciando aquellos casos en que es el ámbito social donde se encuentra el sujeto obliga a la desconexión, podríamos distinguir dos eventualidades:

- Se apaga inespecíficamente: la función perlocutiva y el significante adscrito, en este caso, tendrían que ver con deseos de aislamiento (por trabajo, descanso, intimidad, estado anímico, etc.)

- Se apaga selectivamente para no recibir ni la información de que alguien concreto llama, y para que esa persona sepa que no se conoce su intención de comunicarse (lo que la diferencia de recibir la llamada y no atenderla). Esta conducta tiene relación con agresión, poder, evitación, etc.

\section{CONCLUYENDO:}

Volvamos al inicio:

"Telefonía móvil. Una nueva era”. ¿ En lo tecnológico, lo económico, lo social...?. El texto aclara "La madurez de la telefonía móvil, que ha tenido una niñez muy rápida, está suponiendo y va a suponer aún más en un futuro ya casi inmediato, todo un cambio fundamental, tanto en las RELACIONES SOCIALES como en el mundillo de los negocios..."(2001:1) ¿De qué forma? ¿Hasta qué punto? ????. Surgen múltiples interrogantes.

Tras el análisis realizado, no considero que hasta el momento actual, e incluso hasta donde la vista alcanza, la Telefonía Móvil en general, e incluso ese simpático/odioso objeto a su servicio, el Móvil, en particular, CAMBIEN FUNDAMENTALMENTE LAS RELACIONES SOCIALES.

Como todo objeto, en mi opinión, el teléfono móvil no lleva inscrita en su propia naturaleza un modo de utilización inevitable o unos radicales capaces de introducir cambios esenciales en la existencia humana.

Dicho esto, los cambios psicológicos, sociales, psicosociales y culturales más significativos que podemos atribuir a esta tecnología (y aquí me permito abordarlo con cierto sentido del humor) o que puede vislumbrarse que producirán serían:

- Cambio en el mobiliario urbano. Podremos contemplar en nuestras ciudades esculturas vivientes, quietas, aisladas, deambulando abstraídas, circunspectas o sonrientes, chillonas o silentes.

- Aumento del peso en los bolsos femeninos/masculinos, o inclusión en la moda de un nuevo bolsillo o complemento ad hoc.

- Aumento de las posibilidades de autoagresión, por olvidarse o perder el nuevo y valioso objeto; no solo por la torpeza o el descalabro económico que supone sino por la dependencia que vamos creando de la agenda o del número correspondiente y proporcionado a los elegidos “¿Cómo funcionaré sin MI móvil? Como consecuencia más estrés.

- Problemas de reciclaje (las técnicas y nuevas ideas para resolver este problema ya se han tratado en la prensa). Salen modelos nuevos o, como todo 
elemento "caducable", deja de funcionar; pero sobre todo hay que seguir consumiendo. Y que conste que yo tengo móvil, coche, lavadora y microondas.

- Gracias al móvil podremos distinguir mejor los sujetos respetuosos de los agresivos sociales (creo que no necesita aclaración).

- Aporta un nuevo elemento para la diferenciación/identificación y el estatus.

- "Estimula" nuestro afán productivo para aumentar los ingresos económicos e incluir en los gastos mensuales las cuotas o tarjetas de 2 a 4.,5,6..., teléfonos móviles, y cuando creemos que, al menos, tenemos el terminal, alguien lo pierde o lo estropea.

- Incrementa y enriquece la contaminación acústica, sobre todo en los lugares cerrados, Y, desde una perspectiva psicológica, facilita la escapada del "silencio", en un entorno que cada vez lo soporta peor.

- Favorece la creatividad lingüística de nuestros jóvenes y su concentración en proyectos personales.

- Permite aprovechar el tiempo, resolviendo gestiones en situaciones que obligaban a la pasividad, (esperas, colas, etc.); aunque también permite distraerse y perderlo o huir de actividades que requieran un mayor esfuerzo.

En un tono más serio pero no por ello menos sincero:

- Permite afrontar un mayor número de experiencias que comportan, de forma absoluta o relativa, factores de riesgo, a un más amplio grupo de población, disminuyendo significativamente e incluso eliminando las consecuencias lesivas que pueden ocasionar la aparición de determinadas eventualidades.

En este aspecto YA ES IMPAGABLE, y justifica por si solo, la existencia y aceptación del Móvil, su influencia decisiva en la feliz resolución de situaciones críticas (catástrofes, secuestros, etc.). Rompe el aislamiento forzoso, elimina el "silencio" de la imposibilidad de contacto y por tanto disminuye o disuelve la ANGUSTIA.

Por esta función, inherente a sus características, el buen uso del Móvil influye e influirá significativamente en las vivencias de SEGURIDAD Y LIBERTAD

- Ya las nuevas generaciones de móviles permiten el acceso a Internet, por tanto a mayor información en cualquier momento o lugar, lo que en sentido positivo se traduce en una mayor OPERATIVIDAD Y LIBERTAD.

- Y por último introduce nuevos elementos de interactuación y comunicación, modificándola ¿Cuantitativa o cualitativamente?

Me comprometo a seguir este análisis con la observación y los datos que la investigación nos proporcione. 


\section{Bibliografía:}

- Argyle, M.: Psicología del comportamiento interpersonal. Madrid, Alianza Editorial, 1994.

- Baron,R.A., Byrne, D.: Psicología Social. Madrid, Prentice Hall, 1998.

- Bleger, J.: Psicología de la Conducta. Buenos Aires, Paidós, 1996.

- Castilla del Pino, C: Dialéctica de la persona, dialéctica de la situación. Barcelona, Ed. Península, 1972.

- Castilla del Pino, C.: El Silencio.(Compilación).Madrid, Alianza Editorial, 1.992

- Hartman, H.: Ensayos sobre la psicología del yo. México, Biblioteca de Psicología y Psicoanálisis, 1969

- Latorre Postigo,J.M.: Ciencias Psicosociales Aplicadas. T. II. Madrid, Síntesis, 1995 .

- Lopez -Ibor, J.J.,Ortiz Alonso,T., Lopez-Ibor Alcocer, M ${ }^{\mathrm{a}}$ I.: Lecciones de Psicología Médica. Barcelona, Masson, 1999.

- Mayor, J., Pinillos, J.L., Ibañez, E., Pelechano, V.: Tratado de Psicología General. "Personalidad". Madrid, Alhambra Universal, 1989

- Von Weizaker, K.F: El hombre en su historia. Barcelona, Galaxia Gutemberg, 1993

- Wamba Magallanes, F: La existencia humana: Perspectivas Psicopatológicas. Universidad de Sevilla, 1998.

\section{Revistas}

Anuario El Mundo 2001.

Nueva Economía; ne.com 2001.

El Mundo Digital. Sociedad. 16 de febrero y 3 de noviembre de 2000

Revista de Psicopatología. Vol. 20. № 1, Enero-Marzo de 2000 